\title{
MEYERS Albert e Isabelle cOMBÈs (comps.), El Fuerte de
} Samaipata: estudios arqueológicos

Universidad Autónoma Gabriel René Moreno (Biblioteca del Museo de Historia), Santa Cruz de la Sierra, 2015, 192 p., bibliogr., índice de autores, 141 ilustraciones en color y en blanco y negro (fotos, croquis, mapas, dibujos, recreaciones digitales).

\section{Vera Tyuleneva}

\section{(2) OpenEdition Journals}

\section{Edición electrónica}

URL: https://journals.openedition.org/jsa/14724

DOI: $10.4000 /$ jsa. 14724

ISSN: 1957-7842

\section{Editor}

Société des américanistes

\section{Edición impresa}

Fecha de publicación: 31 octubre 2016

Paginación: 230-235

ISSN: 0037-9174

\section{Referencia electrónica}

Vera Tyuleneva, «MEYers Albert e Isabelle combès (comps.), El Fuerte de Samaipata: estudios arqueológicos», Journal de la Société des américanistes [En línea], 102-1 | 2016, Publicado el 05 diciembre 2016, consultado el 03 septiembre 2022. URL: http://journals.openedition.org/jsa/14724 ; DOI: https://doi.org/10.4000/jsa.14724

Este documento fue generado automáticamente el 3 septiembre 2022.

All rights reserved 


\section{MEYERS Albert e Isabelle COMBÈs (comps.), El Fuerte de Samaipata: estudios arqueológicos}

Universidad Autónoma Gabriel René Moreno (Biblioteca del Museo de Historia), Santa Cruz de la Sierra, 2015, 192 p., bibliogr., índice de autores, 141 ilustraciones en color y en blanco y negro (fotos, croquis, mapas, dibujos, recreaciones digitales).

\section{Vera Tyuleneva}

\section{REFERENCIA}

MEYERS Albert e Isabelle COMBÈs (comps.), El Fuerte de Samaipata: estudios arqueológicos, Universidad Autónoma Gabriel René Moreno (Biblioteca del Museo de Historia), Santa Cruz de la Sierra, 2015, 192 p., bibliogr., índice de autores, 141 ilustraciones en color y en blanco y negro (fotos, croquis, mapas, dibujos, recreaciones digitales).

1 El llamado « Fuerte de Samaipata » es actualmente el segundo monumento arqueológico más conocido y visitado de Bolivia después de Tiahuanaco. Su fama se debe no solamente a las considerables dimensiones del sitio y a su singular ubicación en el límite entre los Andes y las Tierras Bajas, sino en especial a la inusual naturaleza de su elemento central: la gigantesca roca arenisca cubierta de tallados. Generalmente se afirma que Samaipata marcó la expansión inca hacia el sudeste, en la zona de contactos y conflictos con los grupos guaraní, arawak y otras etnias de las tierras bajas.

2 Si bien « el Fuerte » llamó la atención de los viajeros desde el siglo XVIII, tan sólo en la segunda mitad del sigloxx se convirtió en objeto de estudios arqueológicos sistemáticos, luego de haber sido declarado en 1951 Monumento Nacional por el gobierno boliviano. Sin embargo, el aporte más contundente a la arqueología de Samaipata data de los años 1992-1996, en los cuales la misión alemana de la Universidad de Bonn, a cargo de Albert Meyers, condujo allí excavaciones durante cinco temporadas, 
en el marco del Proyecto de Investigaciones Arqueológicas en Samaipata (PIAS). A raíz de los avances del proyecto, en 1998 el monumento fue reconocido por la Unesco como Patrimonio de la Humanidad.

3 Al cabo de veinte años los resultados del trabajo de PIAS finalmente vieron la luz, reunidos en este volumen y enriquecidos con algunos aportes posteriores de otros investigadores. Como señala el título de la compilación, su eje principal es la arqueología de Samaipata; sin embargo algunos de los artículos que la componen abordan temas históricos, problemáticas de conservación, puntos polémicos de la metodología interdisciplinaria e incluso la tradición folclórica que se ha formado en torno del sitio. Los artículos son acompañados de abundante material ilustrativo, el grueso del cual, obviamente, corresponde al registro gráfico de las labores arqueológicas. El libro abre a la vez la nueva colección titulada "Biblioteca del Museo de Historia », instituida por la Universidad Autónoma Gabriel René Moreno de Santa Cruz de la Sierra.

4 El texto introductorio ("El Fuerte» de Samaipata, Patrimonio de la Humanidad: una breve descripción), es escrito por cuatro autores: Albert Meyers, María de los Ángeles Muñoz, Javier Gonzales y Cornelius Ulbert. Ofrece una primera aproximación a la materia desde varias perspectivas disciplinarias. Comienza, en calidad de preámbulo, con un análisis de las fuentes históricas coloniales, entre las cuales desempeña el papel protagónico la afamada pero discutible «Relación cierta » de Diego Felipe de Alcaya, del año 1636. Este texto hace una indudable alusión a Samaipata como punto de control incaico vinculado con unas ricas minas de plata en la zona aledaña. Según Alcaya, tanto Samaipata como las minas fueron atacados y saqueados por los belicosos chiriguana en la víspera de la conquista española. Dentro del sistema administrativo imperial, los autores del artículo no limitan la función del « fuerte » a la de un puesto fronterizo, sino que le atribuyen el papel de capital de una vasta provincia. Al mismo tiempo, resaltan la existencia de material arqueológico anterior a la presencia inca, de diferentes filiaciones culturales, y recalcan el hecho de que en la Colonia temprana el lugar haya tenido una breve ocupación española. Fue precisamente en esa última época, en el contexto de las guerras españolas contra los chiriguana, en la cual fue acuñada la etiqueta " fuerte », que ha quedado adherida al sitio hasta el día de hoy. Por fin, el artículo brinda un resumen historiográfico de los escritos científicos sobre Samaipata y la descripción del monumento por sectores, entre los cuales sobresalen, grosso modo, la roca tallada, presumiblemente de función ceremonial, y varios grupos de construcciones ubicadas al sur de la misma, que constituían áreas residenciales, administrativas y agrícolas.

El segundo artículo (La roca esculpida del Fuerte de Samaipata: Elementos de discusión para un enfoque interpretativo), de Rolando Marulanda, resume algunos puntos desarrollados en la tesis doctoral del autor. Su análisis se centra tanto en los aspectos formales como en las deducciones acerca de la función y el simbolismo de la roca tallada. Traza una lógica comparación entre Samaipata y otros sitios arqueológicos incas que contienen rocas con tallados de formas similares, en su mayoría concentrados en los alrededores del Cusco: Saqsaywaman, Qenqo y Saywite. El autor supone que algunos segmentos de los tallados de Samaipata, que no encuentran analogías claras en los monumentos cusqueños, pueden ser anteriores a la ocupación inca. Entre ellos incluye la famosa estructura circular, ubicada en la parte más prominente de la roca de Samaipata y conocida hoy en día como « el Coro de los Sacerdotes ». Confirmando las observaciones de otros autores del mismo volumen, Marulanda sugiere a la vez que los tallados y las estructuras arquitectónicas asociadas con ellas fueron concluidos en varias (por lo menos 
dos) etapas, con la parcial destrucción y alteración de las formas más tempranas durante las fases tardías. Otro comentario del autor que cabe recalcar es la organización de espacios sobre y alrededor de la roca, en función de la circulación de personas y de sustancias líquidas que probablemente se vertían en los canales y reservorios tallados en el contexto de su uso ritual.

El tercer trabajo (Los trabajos arqueológicos en « el fuerte de Samaipata », 1992-1996) es escrito por Albert Meyers, director del PIAS, y brinda el compendio más amplio y detallado de los datos sobre las excavaciones realizadas en el marco del proyecto así como también sus conclusiones preliminares. A modo de prefacio, el autor habla de los aspectos organizativos del PIAS y de sus objetivos. El primero y fundamental de esos objetivos fue el registro pormenorizado, con la elaboración de un plano, de la roca tallada y los conjuntos arquitectónicos adyacentes. El segundo consistió en aclarar la función del sitio y establecer las pautas de su cronología. El cuerpo principal del artículo describe las excavaciones y los hallazgos en los puntos inmediatamente colindantes con la roca tallada desde los lados sur y este, con el acento en el lugar donde fue emplazada la casa española en el período colonial: en torno de los muros construidos encima de la roca tallada, en una plataforma adyacente, y en torno de la gran plaza frente a la cual está ubicado el edificio más grande del conjunto, la kallanka. Sumando los resultados de las excavaciones, Meyers obtiene la conclusión de que hay dos fases claramente identificables de la presencia Inca en Samaipata, precedidas por varias ocupaciones anteriores, quizás desde el período formativo (aunque la cerámica clasificada como formativa fue encontrada en contextos redepositados). Entre las evidencias de la ocupación preincaica, algunas parecen apuntar hacia los grupos de origen amazónico. El final de la segunda ocupación inca está marcado por una destrucción, hazaña que el autor atribuye a los chiriguana, en cuyas manos pudo haber caído Samaipata después del colapso del Tawantinsuyu, y quienes aparentemente permanecieron allí durante varias décadas, antes de ser expulsados a su vez por los españoles.

7 Los dos artículos que siguen son dedicados a los frutos de las excavaciones en tres sectores específicos. El aporte de Józef Szykulski (Investigaciones en los sectores 1 y 2) describe dos áreas separadas. La primera, ubicada al norte de la roca esculpida, arroja datos bastante escuetos, dado que la actividad humana ahí parece haber sido limitada. Sin embargo, el sector 2, al sur de la roca, proporciona información que permitió al autor construir una secuencia de seis fases de ocupación. Las primeras dos son anteriores a la expansión incaica, y la segunda de ellas parece corresponder a un grupo de filiación amazónica, con habitantes de cabañas hechas de material perecible, de las cuales se conservaron hoyos de postes. La tercera fase transitoria es seguida por la cuarta y la quinta, que corresponden a las dos ocupaciones incas ya señaladas por Meyers, mientras que la sexta corrobora la idea de la invasión de los grupos del oriente luego de la caída del imperio.

Por su parte, María de los Ángeles Muñoz (Una mirada a Samaipata a través de su kallanka, símbolo de la arquitectura de poder inca) se dedica específicamente al mencionado edificio y a sus extraordinarias dimensiones $(68 \times 16$ metros, altura calculada: 12 metros). Estructuras de este tipo se encuentran en muchos asentamientos incas, especialmente en centros administrativos, y aparentemente servían para usos diversos. Su principal finalidad común era alojar de manera simultánea a multitudes de gente, que en algunos casos podían ser soldados, en otros peregrinos o hasta participantes de grandes celebraciones sociales. El análisis de la kallanka de Samaipata 
está centrado principalmente en sus aspectos arquitectónicos. Las excavaciones dentro del edificio permitieron localizar dos hileras de postes que sostenían el techo y dividían el espacio interior en tres naves. Son sumamente interesantes las conclusiones de la autora acerca del posible sistema del techado, en el cual ella percibe un parecido con la estructura de las malocas de algunos grupos amazónicos.

El siguiente texto (La conservación de la Roca Sagrada de Samaipata), de Sonia Avilés, no forma parte de las investigaciones del PIAS, sino que muestra algunos resultados preliminares de otro proyecto, mucho más reciente, que comenzó en 2013, en curso al momento de la publicación del volumen. Patrocinado por la Universidad de Boloña, este proyecto se concentra en la conservación de la roca tallada que, debido a la fragilidad y porosidad natural de la piedra arenisca, se encuentra en estado de deterioro progresivo. Como medida preventiva, hace unos años se prohibió el acceso de los visitantes. Sin embargo, la erosión sigue avanzando debido a factores naturales: las reacciones químicas, el viento, el cambio de temperaturas, los líquenes, las plantas superiores y los insectos. En la segunda mitad del siglo xx se hicieron varias recomendaciones acerca de los métodos de consolidación de la roca. Entre las medidas sugeridas se propone el tratamiento con suspensión de hidróxido de calcio en agua («leche de cal»), en combinación con algunas sustancias naturales (jugo de nopal). Sin embargo, en el centro del proyecto hay métodos de consolidación más actualizados, principalmente el uso del silicato de etilo. Para apreciar la viabilidad de diferentes productos consolidantes, derivados de esa sustancia, se realizaron pruebas de laboratorio en Italia con muestras tomadas de la roca de Samaipata, que dieron resultados alentadores.

El artículo que concluye el volumen es un trabajo adicional de Albert Meyers (Hacia una periodización de la cultura inca: perspectivas desde Samaipata). Tanto por su tenor como por sus objetivos, este texto es totalmente distinto del primero, e indudablemente el aporte interpretativo más ambicioso y sugestivo del libro. Sus conclusiones parten del contexto local de Samaipata, pero su principal meta es replantear íntegramente la percepción tradicional y consagrada de la evolución del Horizonte Tardío. En lo que corresponde específicamente a Samaipata, podrían resaltarse las siguientes consideraciones: 1. Tanto en la roca tallada como en el material obtenido de las excavaciones se observan dos fases claramente separadas de presencia incaica, precedidas por una o varias fases de ocupación anterior. 2. Las dos fases incas son marcadamente distintas: la segunda, a la que pertenece la mayor parte de los tallados en roca y estructuras arquitectónicas, trata de imponerse a la primera, lo cual, quizás, pueda ser interpretado como una ruptura en el contexto religioso o ideológico. Por otra parte, lo que plantea Meyers en cuanto a la visión general del Horizonte Tardío puede resumirse en los siguientes puntos: 1. Es un error concebir el desarrollo del estado incaico exclusivamente desde la posición "centralista ", es decir desde el Cusco; una mirada desde las periferias puede (y debe) cambiar totalmente el panorama. 2. Es necesario analizar por separado las fuentes históricas y el material arqueológico, llegando a puntos de comparación tan sólo en las conclusiones: hay que crear un modelo del Horizonte Tardío basado exclusivamente en los datos de la arqueología, sin usar de muletillas las eventuales fechas de los dudosos reinados. 3. Una de las falencias más grandes del concepto actual de la historia inca es la idea de su "embotellamiento » en sus fases tempranas: un supuesto desarrollo autónomo y hermético en el valle del Cusco hasta el momento de su "explosión» y propagación con las conquistas imperiales. Como alternativa, Meyers sugiere rastrear la emergencia y evolución paulatina de la cultura material inca desde los comienzos del Período Intermedio Tardío, sobre la base de 
diversas tradiciones del Sur Andino, que abarcaban un territorio muy amplio (entre ellas es mencionada la cultura mollo del piedemonte andino-amazónico), y que surgieron a raíz de la desintegración de la tradición Tiahuanaco-Huari. 4. La cultura material inca del período de la expansión no es homogénea, sino que está marcada por matices locales, fases cronológicas sucesivas que a veces pueden señalar rupturas y conflictos internos, para los cuales suele ser inútil buscar correspondencias en documentos históricos. Este texto, en suma, manifiesta un claro desafío al establishment de los estudios andinos e invita a un debate que podría resultar sumamente fértil y productivo.

11 Finalmente, a modo de anexo, el libro incluye un cuento anotado a comienzos del siglo xx por Erland Nordenskiöld, que muestra apenas un solo ejemplo de la frondosa tradición oral sobre los tesoros antiguos que ha estado floreciendo en torno del « fuerte » de Samaipata, al igual que alrededor de muchos otros sitios arqueológicos de los Andes.

Indudablemente, esta compilación es un hito sustancial en la historia de los estudios de Samaipata y del Oriente Boliviano en general. Y más allá de la problemática regional, es un excelente ejemplo de la perspectiva " periférica » sobre la historia y arqueología del Tawantinsuyu, perspectiva que en los últimos años está cobrando cada vez mayor fuerza y que con el tiempo puede transformar totalmente nuestra percepción de la dinámica cultural en el período prehispánico tardío.

\section{AUTORES}

\section{VERA TYULENEVA}

Universidad San Ignacio de Loyola, Extensión Cusco, Perú 